\title{
Interactive comment on "New insights on the early Mesozoic evolution of multiple tectonic regimes in the northeastern North China Craton from the detrital zircon provenance of sedimentary strata" by Yi Ni Wang et al.
}

\author{
W. Xiao (Referee) \\ wj-xiao@mail.iggcas.ac.cn
}

Received and published: 12 September 2018

General comments The early Mesozoic evolution of multiple tectonic regimes in the northeastern North China Craton is of key importance for a better understanding of the tectonics of $E$ Asia including the final closure of the Paleo- Asian Ocean in the CAOB $(\mathrm{XMOB})$ and the onset of the subduction of the Pacific ocean, which are controversial in the international community. This paper presents new detrital zircon $\mathrm{U}-\mathrm{Pb}$ dating and $\mathrm{Hf}$ isotopic data of the Early Mesozoic strata in NE North China Craton in order to address the above issues. The authors define that the Early Triassic deposition was 
controlled primarily by southward subduction of the Paleo-Asian oceanic plate beneath the NCC, and collision between the NCC and the Yangtze Craton (YC). They also infer that rapid uplift of the XMOB and the onset of subduction of the Paleo-Pacific Plate beneath Eurasia occurred in the Early Jurassic. I enjoy reading this manuscript featured with good quality of zircon $\mathrm{U}-\mathrm{Pb}$ ages and $\mathrm{Hf}$ isotopic data. Therefore, I would like to recommend the manuscript to bef published in Solid Earth Discussions after a minor to moderate revision.

Specific comments * While the closure of the Paleo-Asian ocean has been nicely defined by the data in this work, consistent with some other evidence in the literature, the reader is not easier to catch another important conclusion that the onset of subduction of the Paleo-Pacific Plate beneath Eurasia occurred in the Early Jurassic. Although it is mentioned that there is the presence of an Early Jurassic accretionary complex, but it is not on any of the figures, which makes it hard to follow. More importantly, why and how the data in the current work verify the Early Jurassic subduction is not clearly explained. Please have more arguments or explanations.

* $\mathrm{XMOB}$ is well known in China, but less commonly used in the international community, while the Central Asian Orogenic Belt (CAOB) is more commonly used. I would like to suggest, in order to enhance the international readship for the current work, at least add $\mathrm{CAOB}$ after it, namely, $\mathrm{XMOB}$ (eastern $\mathrm{CAOB}$ ) or any other types of connection between these two terms.

P. 10, L 15: better use "confirm" instead of "determine".

P. 14, L 10: add some refs after "remain controversial".

Fig. 1: spell all the acronyms. Spell JJOB in caption. Also should mark the various terranes (such as JM: Jiamusi Massif; KM: Khanka Massif) in this map otherwise the tectonic evolution model with these terranes in Fig. 12 is hard to follow.

Fig. 5: what are the numbers in circles? Please explain either in captions or directly on 
the figure(s).

Fig. 10: Please mark CAOB in the north and Qinling-Dabie in the south, together with all the faults in particular the Tan-Lu Fault, in the map. "Upper" and "lower" are spelled sometimes all small letters, but sometimes with first latter capital; make them in consistency.

Fig. 11: add the ages of these formations or a time bar beside them so that the reader can easily judge the detrital zircon ages and their provenance implications.

Fig. 12: spell all the acronyms directly in the figure or sub-figures so that the reader can immediately catch the tectonic scenario. All subduction zones should be marked in this figure or sub-figures. The presence of an Early Jurassic accretionary complex mentioned in the text should be marked. North mark is too distorted to see; just $\mathrm{N}$ is enough.

\section{Wenjiao Xiao}

Interactive comment on Solid Earth Discuss., https://doi.org/10.5194/se-2018-75, 2018. 